\title{
From open packing to negative wound pressure therapy. A critical overview of deep sternal wound infection treatment strategies after cardiac surgery
}

\author{
Martin Simek ${ }^{\mathrm{a}, \mathrm{b}}$, Adam Chudoba ${ }^{\mathrm{b}}$, Roman Hajek ${ }^{\mathrm{a}}$, Patrick Tobbiac, Martin Molitor ${ }^{\mathrm{d}}$, Petr Nemec
}

Deep sternal wound infection is a challenging aspect of modern cardiac surgery. The considerable mortality rate, devastating morbidity and, negative impact on long-term survival has driven cardiac and plastic surgeons to seek a more advantageous treatment solution. This review summarizes progress in the field of deep sternal wound infection treatment after cardiac surgery. Emphasis is placed on outcomes analysis of contemporary treatment strategy based on negative pressure wound therapy followed by sternotomy wound reconstruction, and its comparison with conventional treatment modalities used afore. Furthermore, complications and drawbacks of treatment strategies are critically evaluated to outline current options for successfully managing this life-threatening complication following cardiac surgery

Key words: sternal wound infection, conventional treatment, pressure wound therapy

Received: April 23, 2018; Accepted with revision: September 5, 2018; Available online: September 14, 2018

https://doi.org/10.5507/bp.2018.053

${ }^{a}$ Department of Cardiac Surgery, University Hospital Olomouc, Czech Republic

${ }^{b}$ Faculty of Medicine and Dentistry, Palacky University Olomouc, Czech Republic

'Department of Cardiovascular Medicine, Regional Medical Center, 624 Hospital Drive, Mountain Home, United States

${ }^{d}$ Department of Plastic Surgery, Hospital Na Bulovce, Prague, Czech Republic

${ }^{e}$ Centre for Cardiovascular and Transplant Surgery, Brno, Czech Republic

Corresponding author: Martin Simek, e-mail:martin.simek@c-mail.cz

\section{INTRODUCTION}

Deep sternal wound infection (DSWI) is a serious complication of cardiac surgery. Even with implementation of modern treatment strategies, in-hospital mortality of DSWI widely ranges between $5.1-19 \%$ (ref. ${ }^{1}$ ). A major factor concerning the care of DSWI's patients is the considerable increase in morbidity linked to prolonged ICU and in-hospital stay and rate of re-interventions. Moreover, development of late complications deteriorates patients' quality of life and requires further in-hospital and out-patient care ${ }^{2}$. The result is a three-fold increase in healthcare costs and a negative impact on long-term survival of patients who have successfully overcome DSWI (ref. $\left.{ }^{2,3}\right)$. Treatment of DSWI has evolved from being based on conventional treatment with closed irrigation or application of muscle or omental flap after sternotomy wound debridement to primary application of negative pressure wound therapy followed by stable sternotomy wound reconstruction ${ }^{1}$.

\section{Conventional treatment (CT)}

Until the beginning of the 1960s, DSWI patients were treated either conservatively, which included antibiotic treatment and eventually limited drainage, or by open dressing of the exposed sternotomy wound until being closed with granulation tissue (open packing). This resulted in a $50 \%$ mortality and devastating morbidity of survivors related to chest wall instability and complicated wound healing ${ }^{4}$. In 1964, Shumacker and Mandelbaum reported their experience with continuous antibiotic ir- rigation in two patients ${ }^{5}$. The treatment consisted of complete sternotomy revision and removal of osteosynthetic material. After the debridement, the sternotomy wound was irrigated with an antibiotic solution, closed by sternal re-wiring and continuously irrigated through indwelling drains. The original method was subsequently modified in terms of the setting and the number of indwelling drains used for irrigation, the type of antiseptic or antibiotic solution used and the type of sternal re-wiring technique performed ${ }^{6,7}$. Targeted antibiotic therapy was part of the treatment. This strategy of treatment was consequently called closed irrigation and became widely used for DSWI, especially in Europe. The reason behind its popularity lies in its simplicity and direct stabilization of the chest. Reported mortality of closed irrigation ranged between $4.8-28 \%$, nevertheless the treatment was linked to failure in $12.5-48 \%$ of cases, which correlates with the type of DSWI according to Oakley and Wright classification $^{7-10}$. Age over 75 (OR 1.01; 1.02-1.18; $P=0.01$ ), renal failure (OR 4.8; 1.03-22.32; $P=0.04$ ) and MRSA infection (OR 6.8; 1.04-44.48; $P=0.05$ ) were identified to be independent predictors of closed irrigation failure ${ }^{9}$.

In 1976, Lee successfully used part of the greater omentum to cover an infected sternotomy wound after closed irrigation therapy had failed ${ }^{11}$. After the sternal wound debridement, fixation of the omentum to rest of the skeletal structures was made, followed by soft tissue closure by secondary intention. Omentum was used as the flap due to its high vascularity, which provides its absorptive abilities as well as high local antibiotic availability. Technically, it is possible to use the entire greater 
omentum on its long vessel pedicle, which allows for filling of deep cavities or covering large superficial defects ${ }^{12}$. Drawbacks of using the omentum include abdominal cavity opening and, furthermore, its edema which may result in delayed primary wound closure or need for dermo-epidermal grafting ${ }^{13}$.

At the beginning of the 1980 s, several reasons (e.g. negative effects on respiration mechanics, inability to mobilize patients, and increased risk of mediastinal structures injury during re-dressing or coughing) led Jurkiewicz to modify the approach of open packing wound management. He implemented a single-stage procedure which combines extensive debridement of sternotomy wound and its covering by using muscle flap, or alternatively in combination with omental flap ${ }^{14}$. Results of 409 patients with DSWI published over 20 years showed an $8.1 \%$ in-hospital mortality and merely $5.1 \%$ risk of primary DSWI treatment failure ${ }^{15}$. Transfer of both pectoral muscles was used in $79.4 \%$ of cases, whereas the rectus abdominis muscle advancement was utilized in $19.4 \%$ of cases. The greater omentum was used in only $2.2 \%$ of cases ${ }^{15}$. Afterwards, the treatment strategy was modified by numerous groups, particularly with respect to the debridement extent, the type of flap used and the timing of wound closure. Published mortality of these modifications ranged between $6.4-19 \%$ and risk of treatment failure between 4.4-11.2\% (ref. ${ }^{15-17}$ ). Extensive sternal debridement resulted in a lower risk of treatment failure when compared to closed irrigation. Nevertheless, even after successful healing of the sternotomy wound, more than half of the patients complained about chronic pain, increased skin sensitivity as well as rib cage instability. Moreover, a third of patients indicated shoulder weakness in connection with pectoral muscles de-insertion ${ }^{18}$. Usage of the omental flap over the pectoral muscles resulted in lower in-hospital mortality ( 4.8 vs. $10.5 \%, P<0.05$ ), lower incidence of muscle flap harvest complications (9.5 vs. $27.7 \%, P<0.0001)$ and shorter in-hospital stay (10.7 vs. 18.8 days, $P<0.05$ ) (ref. ${ }^{19,20}$ ). Sepsis (OR 11.2, $P<0.0001$ ), MOF (OR 9.4, $P=0.001$ ), ICU length of stay greater than 96 hours (OR 7.58, $P=0.007$ ) as well as late presentation of DSWI over 20 days (OR 35.5, $P<0.001$ ) were identified as independent mortality predictors with this treatment $^{5,21}$.

At the end of the 1990s, Oakley and Wright published a DSWI classification system for DSWI treatment stratification in the CT era ${ }^{10}$. The authors based it on retrospective comparative analyses results of closed irrigation with primary muscle flap covering. These showed comparable mortality results in early DSWI forms with absence of risk factors (class I and II), but with significantly shorter in-ICU stay length and in-hospital stay length in closed irrigation treatment ${ }^{22,23}$. On the other hand, presence of DSWI development risk factors (class III) notably increased risk of closed irrigation failure in comparison to primary muscle flap covering ${ }^{7,24}$. In patients with failure of primary DSWI treatment (class IV) and in late forms of DSWI ( $>6$ weeks, class V), modified open package treatment with delayed reconstruction should be preferred ${ }^{10}$. Nowadays, closed irrigation is used by some centres even for treatment of early DSWI forms possessing no risk factors (class I and II) with satisfactory results ${ }^{25}$. The primary muscle flap covering after extensive debridement, at the present time, was substituted by primary application of negative pressure wound therapy with subsequent sternotomy wound reconstruction.

\section{Negative pressure wound therapy (NPWT)}

In 1997, Obdeijn described the first NPWT usage in 3 patients with DSWI. All the patients were extubated and ventilated spontaneously between re-dressing ${ }^{26}$. The first retrospective comparison of NPWT with closed irrigation in a small cohort was published 3 years later. In the NPWT group, a shorter in-hospital stay and decreased primary treatment failure was recorded ${ }^{27}$. A fairly active Lund's group invented a unified NPWT protocol in DSWI and implemented it into practice. Protection of the mediastinal structures was included in the protocol as well ${ }^{28}$. Afterwards, the group also published results of DSWI patients' long-term survival rates that were, in contrast to CT, comparable with survival of patients without sternotomy wound healing disturbances after cardiac surgery $^{29}$. Results of centres, which systematically focus on NPWT, showed 1.1-5.4\% 30-day, 8-15\% 1-year mortality and $2-8 \%$ risk of primary treatment failure in patients with DSWI (ref. ${ }^{29,30}$ ). Average duration of NPWT ranged between 8-12 days with 4 to 6 surgical revisions followed by NPWT application ${ }^{29,30}$. There are some modifications of the NPWT protocol among centres which differ in type of non-adhesive coverage used to protect mediastinum and, furthermore, differ in timing of sternotomy wound closure. CRP level drop ( $<50 \mathrm{mg} / \mathrm{L})$ together with satisfactory local finding are accepted triggers of sternotomy wound closure ${ }^{31}$. Obesity, renal failure, sepsis and delayed surgical revision were determined to be independent predictors of negative results of NPWT ( ref. $^{32,33}$ ).

\section{Antibiotic treatment}

Antibiotic therapy is an integral part of the treatment strategy, including a focus the on type of agent, its detected sensitivity and pharmacokinetic properties. Although, we know the differences in penetration of various antibiotics, hypo-vital and necrotic tissues, predominantly in skeleton, remain a huge therapeutic problem ${ }^{34}$. A biofilm production by some microbial agents is a recent topic of interest as such agents are basically unaffected by systemic administration of antibiotics ${ }^{35}$. After the sternotomy reconstruction, it is recommended to administer antibiotics orally for the period of 6 weeks to lower the risk of late infection-related complications (fistula) $\left(\right.$ ref. $\left.^{34}\right)$.

\section{Hyperbaric oxygen therapy}

Hyperbaric oxygen therapy (HBO) was successfully used in treatment of DSWI as an adjunct therapy to standardized treatment. Availability and size of hyperbaric chamber remain a logistic problem, mainly in relation to severe conditions patients are $\mathrm{in}^{36}$. Literature describes successful use of HBO in two groups of 55 and 10 patients, respectively, with zero in-hospital mortality ${ }^{37,38}$. On average, between 20-40 cycles of HBO were applied, all 
patients were generally in good condition and the treatment application was made just before closure of the sternotomy wound or due to soft tissues healing disturbances. DSWI caused by anaerobes is a relevant indication as well.

\section{Comparison of negative wound pressure to conventional therapy of DSWI}

Comparison of NPWT efficacy to conventional DSWI therapy has been the focus of many studies. A total of 20 comparative analyses and 6 meta-analyses were found, however, only retrospective non-randomized studies and their meta-analyses are available $27,29,33,39-60$. Moreover, in most of the published studies, obvious heterogeneity in compared patients' and DSWI characteristics was identified. Only in one paper propensity matching to homogenized comparison groups was carried out ${ }^{33}$. Overall, comparative studies confirmed lower risk of therapy failure in NPWT ( $R R=0.34,95 \%$ CI: 0.19-0.59). In addition, recent publications and meta-analyses implied lower mortality rates in comparison to $\mathrm{CT}(\mathrm{RR}=0.40,95 \%$ CI 0.28-0.57) ( ref. $^{61}$ ). Results of published studies and meta-analyses are depicted in detail in Table 1. Recently, NPWT was recommended as a destination therapy or as a bridge prior to sternotomy wound closure in case of DSWI (Class I, Level of Evidence B) according to EACTS expert consensus statement ${ }^{62}$. Furthermore, NPWT was not found to be more expensive in comparison to CT (2.8 times vs. 2.5 times the cost of uncomplicated cardiac surgery, NS) when calculated within Swedish healthcare system $^{63}$. Another group even demonstrated cost reduction in comparison to CT (31 $106 €$ vs. $24383 €, 6723 €$ margin), its results were drawn from Italian healthcare system calculations ${ }^{64}$.

\section{Options for sternotomy wound reconstruction after DSWI in the era of NPWT}

NPWT is a potent tool for wound bed infection control; nevertheless, sternotomy wound reconstruction is another inevitable step towards DSWI healing. Today, the reconstruction is focused on achievement of chest wall stability because it augments soft tissue healing, usage of local muscle flap advancement, and supports function of the auxiliary respiratory muscles ${ }^{47,65,66}$. Recent studies pointed out better quality of life in such patients in comparison to patients whose residual defect was only covered by a muscle flap, however, survival benefit has not yet been proven ${ }^{67-69}$.

Quality and range of sternal lamellae bone loss are the main limitations of chest wall stabilization in DSWI patients. Transsternal or parasternal cerclage insertion and potentially parasternal binding (Robicsek and his modification) require preservation of major portions of sternal lamellae ${ }^{70}$. Furthermore, it is necessary to loosen granulation tissue adhesions in between sternal lamellae and anterior mediastinum, bearing certain risk of bypass graft or heart damage ${ }^{47,66}$. In the last ten years, efforts to lower this risk led to preferential use of plate osteosynthesis and parasternal fixation-enabling systems ${ }^{66}$. In a major published group (92 patients), in which stable plate osteosynthesis was used (Titanium Sternal Fixation System $^{\mathrm{TM}}$, Synthes, Switzerland) for sternotomy wound reconstruction after DSWI, only 9.8\% had their plates removed due to late-onset infection (fistulae). The removal had little to no impact on their chest wall stability $^{47,65}$. Recently published retrospective comparison of sternotomy wound stabilization by titanium plates ( 20 patients) versus coverage by a muscle flap without sternal stabilization (22 patients) proved that the group of patients who underwent the plate osteosynthesis had shorter actual reconstruction procedure duration (138.8 \pm 25.8 vs. $184.3 \pm 75.9 \mathrm{~h}, P=0.009)$ as well as shorter in-hospital stay after the reconstruction had been done $(18.1 \pm 20.6$ vs. $38.9 \pm 39.3$ days, $P=0.025)$. Concerning one-year mortality, there was hardly any significant difference between the two groups ( 15 vs. $27.2 \%, P=0.187$ ). According to questionnaire SF-12, patients with stable plating indicated significantly better quality of life $(42.8 \pm 8.6$ vs. $29.5 \pm 10.7$ points, $P=0.034$ ) ( ref. $^{68}$ ). Moreover, another retrospective study has also proven significantly lower risk of DSWI recurrence in patients with stable plating (36 patients) in comparison with those who had their defect covered by a muscle flap only ( 26 patients) ( 8.9 vs. $40 \%, P=0.02$ ). Shorter in-hospital stay $(22.4 \pm 3.1$ vs. $25.6 \pm 3.1$ days, $P<0.05$ ) was recorded in patients after plating but with insignificant difference in hospital mortality (11.1 vs. $19.2 \%$, $P=0.47$ ) between both groups ${ }^{68}$. An outer parasternal fixation system (Atraumatic Sternum Closure System ${ }^{\mathrm{TM}}$; KS Handelsvertretung Produktinovation, Germany) was successfully implanted in 16 DSWI patients. Its application is simple and needless of extensive pectoral muscle deattachment and sub-sternal dissection, however similarly to wire cerclage, the major sternal lamellae preservation is required ${ }^{71}$.

On the other hand, major residual sternal bone loss or loss of adjacent ribs still possesses a challenge after DSWI treatment, even in the plating era ${ }^{66}$. The bone residue does not allow for either sufficient anchoring for the plates or there is a large bone tissue gap. Shear forces may loosen screws and threaten stability ${ }^{47,66}$. A conventional surgical approach to manage the large residual bone defect leaves the sternotomy wound unstable and employs the greater omentum or pedicled muscle flaps to fill in any dead spac$\mathrm{es}^{67,70}$. However, this approach resulted in sternal instability and flap-related morbidity even when wounds were well-healed ${ }^{66,67}$. Nowadays, autograft or homograft bone replacement and its anchoring with titanium plates is an option for major residual bone defects. Bicortical autologous bone iliac crest graft or fibula graft can be used for smaller defects, cadaverous sternum, potentially sternocostal homografts are, on the other hand, used for fillingin of major defects ${ }^{72-75}$. The first sternal homograft was used by Marulli after sternal chondrosarcoma resection ${ }^{76}$, procedure has progressively been adopted for patients with extensive bone loss due to DSWI (ref. ${ }^{75,76}$ ). Published results show that complete chest stability after bone homograft implantation was achieved in $90 \%$ patients, moreover, a scintigraphy study showed increased accumulation of radiopharmaceuticals in implanted homografts suggesting homograft's conversion to active tissue $e^{66,77}$. Bone 
Table 1. Analyses and meta-analyse of comparison NPWT with CT.

\begin{tabular}{lllll}
\hline Follow-up & Patients' cohort & End-points & Results & Ref. \\
\hline Retrospective & 11 pts NPWT vs. 9 & In-hospital stay, therapy & NPWT linked to shorter in-hospital stay $(15$ vs. 40.5 & 27 \\
& pts closed irrigation & failure & days, $P=0.02)$ and lower therapy failure $(0$ vs. $5 \%$, & $P=0.03)$ than closed irrigation
\end{tabular}

Retrospective 31 pts NPWT vs. Therapy failure, in-hos- NPWT group had a lower risk of therapy failure (52 29 pts closed irriga- pital stay and mortality vs. $16 \%, P<0.05)$ and in-hospital stay ( 22 vs. 26 days, tion $P<0.05$ ), with comparable in-hospital mortality (6.9 vs. $6.6 \%, \mathrm{NS}$ ) to closed irrigation

Retrospective 22 pts NPWT vs. Therapy failure, in-hos- NPWT group had shorter overall length of therapy 22 closed irrigation pital stay and mortality $\quad(17.2 \pm 5.8$ vs. $22.9 \pm 10.8$ days, $P=0.01)$ and in-hospital stay ( $27.9 \pm 6.6$ vs. $33.0 \pm 11.0$ days, $P=0.03)$, with comparable mortality ( 5 vs. $5 \%$, NS) to closed irrigation

Retrospective 17 pts NPWT vs. Therapy failure, number NPWT associated with shorter length of therapy (6.2 18 pts muscle flap of dressing changes, in- vs. 8.5 days, $P<0,05)$, lower number of dressing changes covering hospital stay and mor- ( $3 \pm 2.5$ vs. $17 \pm 8.6, P<0.01)$, and comparable in-hospital tality mortality (11 vs. $6 \%$, NS)

Retrospective 27 pts NPWT vs. Therapy failure, in-hospi- NPWT linked to lower therapeutic failure rate (15 vs. 13 pts closed irriga- tal mortality, and cost of $30.7 \%, P<0.05)$, in-hospital mortality $(7.5 \%$ vs. $18.5 \%$, tion therapy $P<0.05$ ) and overall cost of therapy (16 400 vs. 20000 USD, NS) compared with closed irrigation

Retrospective 35 pts NPWT vs. 33 pts muscle flap covering

Retrospective 61 pts NPWT vs. 40 closed irrigation/muscle flap covering

Retrospective 38 pts NPWT vs. 17 muscle flaps covering

Length to achieve sterile NPWT led to faster bacterial decontamination of wounds wound, length of thera- ( 16 vs. 26 days, $P<0.01$ ), shorter length of therapy ( 21 py, in-hospital stay, and vs. 28 days, $P<0.01)$ and in-hospital stay ( 25 vs. 34 1-year survival days, $P<0.01)$ and better 1-year survival $(97.1$ vs. $74.7 \%$, $P<0.05)$ compared with open packing

Therapy failure, 1- and NPWT had lower risk of therapy failure ( 0 vs.15\%, 5-year mortality $P<0.01$ ), 90-day mortality (0 vs. $15 \%, P<0.01$ ), and 1 and 5 -year survival ( 93 vs. $82 \%, 83$ vs. $59 \%, P<0.05$ ) compared to conventional therapy

In-hospital stay and in- NPWT led to shorter in-hospital stay (51.5 \pm 20.8 vs. hospital mortality, qual- $70.7 \pm 28.8$ days, $P<0.05)$, non-significantly lower in-hosity of life pital mortality ( 5.3 vs 11.8 , NS) and better quality of life based on questionnaire SF-36 compared with sternectomy and flap

Retrospective 29 pts NPWT vs. Therapy failure, in-hospi- NPWT decreased primary therapy failure (27.6 vs. 34 pts closed irriga- tal, and 1-year mortality $58.9 \%, P<0.05$ ), with comparable 30 -day (3.5 vs. $2.9 \%$, tion NS) and 1-year mortality ( 31.0 vs. $23.5 \%$, NS) to closed irrigation

Retrospective 125 pts NPWT vs. 24 pts muscle flap covering

In-hospital mortality Lower mortality in NPWT group ( 4.8 vs. $14.1 \%, P=0.01$ ), and 1-,5-, and 10 years but insignificantly better 1-, 5-, and 10-year survival ( 92.8 survival vs. $83.0 \%, 89.8$ vs. $76.4 \%, 88.0$ vs. $61.3 \%$, NS)

Retrospective 69 pts NPWT vs. 49 closed irrigation

Therapy failure, in-hos- NPWT associated with lower therapeutic failure $(2.9 \%$ pital stay and mortality vs. $18.3 \% P<0.05)$ and in-hospital mortality $(5.8 \%$ vs. $24.5 \% P<0.05$ ), but comparable in-hospital stay ( 38 vs. 41 days, NS) with closed irrigation

Retrospective 38 pts with NPWT vs. 28 pts closed irrigation

Therapy failure, in-hospi- NPWT had lower failure of primary therapy (5.8 vs. tal stay, in-hospital, and $39.2 \%, P<0.05)$, ICU stay $(209.6 \pm 33.3$ vs. $516.1 \pm 449.5 \mathrm{~h}$, 1-year mortality 1 -year mortality $(14.7$ ble in-hospital stay $(40.2 \pm 16.3$ vs. $48.8 \pm 29.2$, NS $)$ with closed irrigation. 
Table 1. Continued

\begin{tabular}{lllll}
\hline Follow-up & Patients' cohort & End-points & Results & Ref. \\
\hline Retrospective & 74 pts NPWT vs. & Therapy failure, in-hos- & NPWT group with lower risk of therapy failure $(1.4$ vs. & 50 \\
& 83 pts closed irriga- & pital stay and mortality & $16.9 \%, P<0.001)$, shorter in-hospital stay $(23.3 \pm 9$ vs. \\
& tion & & $3.0 .5 \pm 3, P<0.05)$, and lower in-hospital mortality $(1.4$
\end{tabular}

Retrospective 82 pts NPWT vs. In-hospital stay and mor- NPWT patients had shorter in-hospital stay (45.6 \pm 18.5 38 closed irrigation tality vs. $55.2 \pm 23.6$ days $P<0.05)$, and lower in-hospital mortality ( 14.6 vs. $32.4 \%, P<0.05)$

Retrospective 89 pts NPWT vs. In-ICU and hospital stay NPWT led to shorter ICU stay (6.8 \pm 14.4 vs. $18.5 \pm 21.0$ 24 muscle flaps and mortality days $P<0.01)$, in-hospital stay $(74.4 \pm 61.2$ vs. $69.1 \pm 62.7$ covering days, $P<0.01)$, and lower in-hospital mortality $(12.4$ vs. $41.7 \%, P<0.01)$

Retrospective 47 pts NPWT vs. Therapy failure, in-hos- NPWT had insignificantly lower rate of primary therapy 43 pts closed irriga- pital stay and 1-, 3 years failure (2.1\% vs. $4.7 \%$, NS) and shorter in-hospital stay tion mortality ( $18 \pm 9$ vs. $24 \pm 10$ days, NS), 90-day mortality significantly lower ( 8.5 vs. $23.2 \%, P<0.05$ ) and better 1 -, and 3-year survival $(91.5 \%$ vs. $76.7 \%, P<0.05,87.2$ vs. $69.8 \%, P<0.05)$

Retrospective 326 pts NPWT vs. 198 pts closed irrigation/muscle flap covering

Retrospective 64 pts NPWT vs. 66 pts closed irrigation

Retrospective 20 pts NPWT vs. 23 pts closed irrigation

Retrospective 22 pts NPWT vs. 22 pts closed irrigation

Meta-analysis

12 papers focused on comparison of NPWT with CT

Meta-analysis 13 papers focused on comparison of NPWT with CT

Meta-analysis 15 papers focused on comparison of NPWT with CT

Meta-analysis 6 papers focused on comparison of NPWT with CT

Meta-analysis 7 papers focused on comparison of NPWT with CT

Meta-analysis 22 non-randomized studies focused on comparison of NPWT (2467 pts) with CT (2233 pts)
Therapy failure, in-hospi- NPWT was associated with lower primary therapy failure tal mortality ( $8.5 \%$ vs. $34 \% P<0.001)$, and in-hospital mortality ( $3.6 \%$ vs. $10 \%, P<0.05)$

Therapy failure, in-hospi- NPWT had lower rate of primary therapy failure ( $6 \%$ vs. tal mortality, and 10 -year $21 \%, P<0.01)$, but comparable 30 -day $(3.1 \%$ vs. $0 \%$, NS) survival mortality and no long-term survival benefit of NPWT

Therapy failure, in-hospi- NPWT was associated with lower primary therapy failure tal and 1 -year mortality ( $5 \%$ vs. $34.8 \%, P=0.02$ ), the 30 -day mortality was not significantly different between groups ( $4 \%$ vs. $0 \%, \mathrm{NS})$ and the same was true for 1-year mortality ( $17 \%$ vs. $0 \%$, NS).

In-hospital mortality, in- NPWT carried significant lower in-hospital mortality ( 5 dependent predictors of vs. $38 \%, P=0.021$ ), NPWT was found to be independent survival predictor of survival (OR $0.062 ; P=0.041$ ) as well as usage of muscle flap for sternotomy wound closure (OR $0.022 ; P=0.048$ )

Therapy failure, in-hos- NPWT was associated with lower primary therapy failpital stay and mortality ure, shorter in-hospital stay, and lower in-hospital and 1-year mortality

Therapy failure, in-hos- NPWT seemed to be effective at high-risk DSWI papital stay and mortality tients, but with weak evidence for routine first-line application in DSWI

Therapy failure, in-hos- NPWT is associated with lower therapeutic failure, and pital stay and mortality in-hospital mortality. Routinely applied as first-line treatment in $35 \%$ of German heart centres

Therapy failure, in-hos- NPWT proved to have shorter in-hospital stay and lower pital stay and mortality mortality

Therapy failure, length NPWT was associated with lower risk of primary therapy of therapy, and in-hospi- failure, shorter in-ICU stay, and comparable in-hospital tal stay stay

Mortality, risk of therapy NPWT was associated with lower mortality rate (RR 0.4, failure, in-hospital stay $\quad 95 \%$ CI $0.28-0.57$ ), lower rate of primary therapy failure (RR 0.34, 95\% CI 0.19-0.59), but no difference in the length of in-hospital stay (RR -2.25, 95\% CI -7.52-3.02) in comparison to $\mathrm{CT}$ 
allograft usage for transplantation is restricted under local governments and European Association of Tissue Banks ${ }^{78}$. Recently a multidirectional thoracic wall stabilization system (STRATOS ${ }^{\text {TM }}$, MedXpert GmbH, Germany) has become available to help repair extensive chest wall defects after tumor resection ${ }^{79}$. The system enables bone defect bridging without needing it to be filled in with bone auto-, homograft, however, the experience of resolving DSWI related sternal defects is, for now, limited ${ }^{80}$.

\section{Complication of DSWI treatment}

Severe bleeding during DSWI therapy is a life-threatening complication. Damage to the right ventricular free wall or to bypasses, less frequently to major vessels, ranks among distinctive bleeding causes. Causes of bleeding might be due to erosion that occurred due to infectious processes; however, mostly mechanical injury plays a part ${ }^{81}$. There is a risk of either direct injury due to sternal lamella or due to pull of adhesion between the right ventricle and sternum when rapid intrathoracic pressure changes come (cough) ( ref. $^{82}$ ). The incidence of severe bleeding ranges between $2-14.8 \%$ in CT and increases with primary muscle flap covering rather than with closed irrigation ${ }^{81,83}$. Recent data showed a 2-6\% risk of this complication during NPWT with the mortality rate varying between $19-55 \%$ (ref. ${ }^{83-85}$ ). Meticulous covering of mediastinal structures with use of non-adhesive interface materials is a vital part of NPWT application in DSWI as well as cough prevention and upper limb movement restriction ${ }^{29,84}$. Some centres recommended routine release of adhesions in between the right ventricle and left sternal lamella as a part of NPWT application proto$\mathrm{col}^{85,86}$. Polyurethane perforated disc $(20 \mathrm{x} 10 \mathrm{x} 0.2 \mathrm{~cm})$ has been recently tested to shield the mediastinum from direct contact with drainage sponge as well as sternal lamellae. Thanks to micro-apertures, mediastinal drainage is not limited by disc ${ }^{87}$. It led to decrease in NPWT duration (3.1 \pm 0.4 vs. $5.4 \pm 0.6$ dressings, $P<0.01$ ), faster decline in CRP levels $(P<0.05)$ and smaller amount of epicardial petechial haemorrhages $(2.3 \pm 2.2$ vs. $5.4 \pm 3.6, P<0.05)$ in comparison with usage of layered non-adhesive interface dressing ${ }^{88,89}$. Data from long-term follow-up suggest that the risk of late infection complications (fistulae) ranged between $8-12 \%$ and became almost equivalent to those seen in NPWT and CT (ref. ${ }^{29,49,65,90,91}$ ). Fistula-related management goes hand in hand with further need for in/out-patient care and cost increase, and according to one study such patients have decreased long-term survival rates $^{90 .}$ Debridement plays a crucial role in the drop of early (failure of DSWI primary therapy failure) and late recurrence (fistula) of DSWI (ref. ${ }^{66,91}$ ). During NPWT, debridement is done repeatedly, and granulation tissue formation is strongly stimulated by negative pressure. On the other hand, improper debridement may lead to granulation tissue overlapping the infected or hypo-vital skeleton parts which can be manifested as infection recurrence, particularly coupled with biofilm-producing agents like Coagulase-negative Staphylococci and Pseudomonas ${ }^{35,90}$.

\section{CONCLUSION}

Robicsek postulated vital DSWI management principles almost 20 years ago including: controlling the infectious process as quickly as possible, proper debridement, effective wound drainage, and the achievement of thoracic wall stability after sternotomy wound reconstruction ${ }^{70}$. However, single approach to the treatment strategy of DSWI has not yet been generally accepted. The possibility to perform debridement repeatedly, unlimited drainage capacity, and strong stimulation of granulation tissue formation within NPWT, together with modern tools of sternal stabilization and bone-/soft tissue reconstruction, draw us closer to Robicsek's postulates. Undoubtedly, DSWI will continue to be a major complication of cardiac surgery. On the other hand, proper and brief infection control preventing MOF development, and stable sternotomy wound reconstruction afterwards are able to provide near-to-comparable long-term outcomes of DSWI patients with those who have had an uncomplicated postoperative course after cardiac surgery.

\section{ABBREVIATIONS}

CT, conventional therapy; EACTS, European Association for Cardio-Thoracic Surgery; DSWI, deep sternal wound infection; ICU, intensive care unit; MRSA, methicillin-resistant Staphylococcus aureus; MOF, multiple organ failure; NPWT, negative pressure wound therapy; NS, statistically non-significant; OR, odds ratio; $\mathrm{RR}$, risk ration.

\section{Search strategy and selection criteria}

Data for this article were identified by searches of PubMed using the mesh words "DSWI treatment", "conventional therapy", "open packing”, "closed irrigation", "muscle flap covering", "negative pressure wound therapy", and "VAC therapy". Preference was given to publications presenting larger cohorts and using sound methodology. Citations from respectable journals were given special weight. English and German language papers were reviewed.

Acknowledgement: This work was supported by $\mathrm{MH} \mathrm{CZ}$ - DRO (FNO1, 00098892).

Author contributions: MS: literature search, manuscript writing and final approval; AC, RH, PT, BZ: literature search; PT: written English correction, PN: critical reading, final approval.

Conflict of interest statement: None declared.

\section{REFERENCES}

1. Cotogni $P$, Barbero C, Rinaldi M. Deep sternal wound infection after cardiac surgery: Evidences and controversies. World J Crit Care Med 2015;4:265-73.

2. Sears ED, Wu L, Waljee JF, Momoh AO, Zhong L, Chung KC. The Impact of Deep Sternal Wound Infection on Mortality and Resource Utilization: A Population-based Study. World J Surg 2016;40:2673-80. 
3. Risnes I, Abdelnoor M, Almdahl SM, Svennevig JL. Mediastinitis after coronary artery bypass grafting risk factors and long-term survival. Ann Thorac Surg 2010;89:1502-10.

4. Sarr MG, Gott VL, Townsend TR. Mediastinal infection after cardiac surgery. Ann Thorac Surg 1984;38:415.

5. Shumacker HB, Mandelbaum I. Continuous antibiotic irrigation in the treatment of infection. Arch Surg 1963;86:384.

6. Merrill WH, Akhter SA, Wolf RK, Schneeberger EW, Flege JB Jr. Simplified treatment of postoperative mediastinitis. Ann Thorac Surg 2004;78:608-12.

7. Poncelet AJ, Lengele B, Delaere B, Zech F, Glineur D, Funken JC, E Khoury G, Noirhomme P. Algorithm for primary closure in sternal wound infection: a single institution 10-year experience.Eur J Cardiothorac Surg 2008;33:232-8.

8. Levi N, Olsen PS. Primary closure of deep sternal wound infection following open heart surgery: a safe operation? J Cardiovasc Surg (Torino) 2000;41:241-5.

9. Kirsch M, Mekontso-Dessap A, Houël R, Giroud E, Hillion ML, Loisance DY. Closed drainage using redon catheters for poststernotomy mediastinitis: results and risk factors for adverse outcome. Ann Thorac Surg 2001;71:1580-6.

10. El Oakley RM, Wright JE. Postoperative mediastinitis: classification and management. Ann Thorac Surg 1996;61:1030-6.

11. Lee AB Jr, Schimert G, Shaktin S, Seigel JH. Total excision of the sternum and thoracic pedicle transposition of the greater omentum useful stratagems in managing severe mediastinal infection following open heart surgery. Surgery 1976;80:433-6.

12. Yasuura K, Okamoto H, Morita S, Ogawa Y, Sawazaki M, Seki A Masumoto H, Matsuura A, Maseki T, Torii S. Results of omental flap transposition for deep sternal wound infection after cardiovascular surgery. Ann Surg 1998;227:455-9.

13. Singh K, Anderson E, Harper JG. Overview and management of sternal wound infection. Semin Plast Surg 2011;25:25-33.

14. Jurkiewicz MJ, Bostwick J, Hester TR, Bishop JB, Craver J. Infected median sternotomy wound: successful treatment by muscle flaps. Ann Surg 1980;191:738-9.

15. Jones G, Jurkiewicz MJ, Bostwick J, Wood R, Bried JT, Culbertson J, Howell R, Eaves F, Carlson G, Nahai F. Management of the infected median sternotomy wound with muscle flaps. The Emory 20-year experience. Ann Surg 1997;225:766-78.

16. Brandt C, Alvarez JM. First-line treatment of deep sternal infection by a plastic surgical approach: superior results compared with conventional cardiac surgical orthodoxy. Plast Reconstr Surg 2002;109:2231-7.

17. Wong CHK, Senewiratne S, Garlick G, Mullany D. Two-stage management of sternal wound infection using bilateral pectoralis major advancement flap. Eur J Cardiothorac Surg 2006;30:148-52

18. Ringelman PR, Vander KC, Cameron D, Bumgartner WA, Manson $\mathrm{PN}$. Long-term results of flap reconstruction in median sternotomy wound infection. Plast Reconstr Surg 1994;93:1208-14.

19. Milano CA, Georgiade G, Muhlbaier LH, Smith PK, Wolfe WG. Comparison of omental and pectoralis flaps for poststernotomy mediastinitis. Ann Thorac Surg 1999;67:377-81.

20. Van Wingerden JJ, Lapid O, Boonstra PW, de Mol BAJM. Muscle flaps or omental flap in the management of deep sternal wound infection. Interact CardioVasc Thorac Surg 2011;13:179-88.

21. De Feo M, Renzulli A, Ismeno G, Gregorio R, Della Corte A, Utili $\mathrm{R}$, Cotrufo $\mathrm{M}$. Variables predicting adverse outcome in patients with deep sternal wound infection. Ann Thorac Surg 2001;71:324-31.

22. Molina E. Primary closure for infected dehiscence of the sternum Ann Thorac Surg 1993;55:459-63.

23. Scully HE, Leclerc $Y$, Martin RD, Tong $C P$, Goldman BS, Weise RD, Mickleborough LL, Baird RJ. Comparison between antibiotic irrigation and mobilization of pectoral muscle flaps in treatment of deep sternal infection. J Thorac Cardiovasc Surg. 1985;90:523-31.

24. Rand RP, Cochran RP, Aziz S, Hofer BO, Allen MD, Verrier ED, Kunzelman KS. Prospective trial of catheter irrigation and muscle flaps for sternal wound infection. Ann Thorac Surg 1998;65:1046-9.

25. Deschka H, Erler S, El-Ayoubi L, Vogel C, Vöhringer L, WimmerGreinecker G. Suction-irrigation drainage: An underestimated therapeutic option for surgical treatment of deep sternal wound infections. Interact Cardiovasc Thorac Surg 2013;17:85-9.

26. Obdeijn MC, de Lange MY, Lichtendahl DH, de Boer WJ.Vacuumassisted closure in the treatment of poststernotomy mediastinitis. Ann Thorac Surg 1999;68:2358-60.
27. Catarino PA, Chamberlain MH, Wright NC, Black E, Campbell K, Robson D, Pillai RG.High-pressure suction drainage via a polyurethane foam in the management of poststernotomy mediastinitis. Ann Thorac Surg 2000;70:1891-5.

28. Gustafsson RI, Sjögren J, Ingemansson R. Deep sternal wound infection: a sternal-sparing technique with vacuum-assisted closure therapy. Ann Thorac Surg 2003;76:2048-53.

29. Sjögren J, Malmsjö M, Gustafsson R, Ingemansson R. Poststernotomy mediastinitis: a review of conventional surgical treatments, vacuum-assisted closure therapy and presentation of the Lund University Hospital mediastinitis algorithm. Eur J Cardiothorac Surg 2006;30:898-905

30. Fleck T, Moidl R, Giovanoli P, Aszmann O, Bartunek A, Blacky A, Grabenwoger $\mathrm{M}$, Wolner $\mathrm{E}$. A conclusion from the first 125 patients treated with the vacuum assisted closure system for postoperative sternal wound infection. Interact Cardiovasc Thorac Surg 2006;5:1458.

31. Gustafsson R, Johnsson $P$, Algotsson L, Blomquist S, Ingemansson R Vacuum-assisted closure therapy guided by C-reactive protein level in patients with deep sternal wound infection. J Thorac Cardiovasc Surg 2002;123:895-900.

32. Sjögren J, Mokhtari A, Gustafsson R, Malmsjö M, Nilsson J, Ingemansson R. Vacuum-assisted closure therapy for deep sternal wound infections: the impact of learning curve on survival and predictors for late mortality. Int Wound J 2008;5:216-23.

33. Morisaki A, Hosono M, Sasaki Y, Hirai H, Sakaguchi M, Nakahira A, Seo $\mathrm{H}$, Suehiro S, Shibata T. Evaluation of risk factors for hospital mortality and current treatment for poststernotomy mediastinitis. Gen Thorac Cardiovasc Surg 2011;59:261-7.

34. Al-Ebrahim KE. Sternocutaneous fistulas after cardiac surgery.Ann Thorac Surg 2010;89:1705-6.

35. Elgharably H, Mann E, Awad H, Ganesh K, Ghatak PD, Gordillo G, SaiSudhakar CB, Roy S, Wozniak DJ, Sen CK.. First evidence of sternal wound biofilm following cardiac surgery. PLoS One 2013;8:e70360.

36. Christian M. The role of hyperbaric oxygen therapy in the treatment of sternal wound infectionEur J Cardiothorac Surg 2006;30:153-9.

37. Siondalski $P$, Keita L, Sicko Z, Zelechowski P, Jaworski L, Rogowski J. Surgical treatment and adjunct hyperbaric therapy to improve healing of wound infection complications after sterno-mediastinitis. Pneumonol Alergol Pol 2003;71:12-6.

38. Litwinowicz R, Bryndza M, Chrapusta A, Kobielska E, Kapelak B Grudzień G. Hyperbaric oxygen therapy as additional treatment in deep sternal wound infections - a single center's experience. Kardiochir Torakochirurgia Pol 2016;13:198-202.

39. Berg H, Brands W, Geldrop T, Kluytmans M, Kluytmans J. Comparison between closed drainage techniques for the treatment of postoperative mediastinitis. Ann Thorac Surg 2000;70:924-9.

40. Doss M, Martens S, Wood JP, Wolff JD, Baier C, Moritz. Vacuumassisted suction drainage versus conventional treatment in the management of poststernotomy osteomyelitis Eur J Cardiothorac Surg 2002;22:934-8.

41. Song DH, Wu LC, Lohman RF, Gottlieb LJ, Franczyk M. Vacuumassisted closure for the treatment of sternal wounds: the bridge between debridement and definitive closure. Plast Reconstr Surg 2003;111:92-7.

42. Luckraz H, Murphy F, Bryant S, Charman S, Ritchie A. Vacuumassisted closure as a treatment modality for infections after cardiac surgery J Thorac Cardiovasc Surg 2003;125:301-5.

43. Fuchs U, Zittermann A, Stuetten B, Groening A, Minami K, Koefer $R$. Clinical outcome of patients with deep sternal infection managed by vacuum-assisted closure compared to conventional therapy with open packing: A retrospective analysis. Ann Thorac Surg 2005;79:526-31.

44. Sjögren J, Gustafsson R, Nilsson J, Malmsjö M, Ingemansson R. Clinical outcome after poststernotomy mediastinitis: vacuumassisted closure versus conventional treatment. Ann Thorac Surg 2005;79:2049-55.

45. Immer FF, Durrer M, Mühlemann KS, Erni D, Gahl B, Carrel TP. Deep sternal wound infection after cardiac surgery: modality of treatment and outcome. Ann Thorac Surg 2005;80:957-61.

46. Segers $\mathrm{P}$, de Jong AP, Kloek JJ, de Mol BAJM. Poststernotomy mediastinitis: comparison of two treatment modalities. Interact Cardiovasc Thorac Surg 2005;4:555-60.

47. Baillot R, Cloutier D, Montalin L, Côté L, Lellouche F, Houde C, Gaudreau G, Voisine P. Impact of deep sternal wound infection 
management with vacuum-assisted closure therapy followed by sternal osteosynthesis: a 15-year review of 23,499 sternotomies. Eur J Cardiothorac Surg 2010;37:880-7.

48. Petzina R, Hoffmann J, Navasardyan A, Malmsjö M, Stamm C, Unbehaun A, Hetzer R. Negative pressure wound therapy for poststernotomy mediastinitis reduces mortality rate and sternal re-infection rate compared to conventional treatment. Eur J Cardiothorac Surg 2010;38:110-3.

49. Simek M, Hajek R, Fluger I, Molitor M, Grulichova J, Langova K, Tobbia P, Nemec P, Zalesak B, Lonsky V. Superiority of topical negative pressure over closed irrigation therapy of deep sternal wound infection in cardiac surgery. J Cardiovasc Surg (Torino) 2012;53:113-20.

50. De Feo M, Della Corte A, Vicchio M, Pirozzi F, Nappi G, Cotrufo M. Is post-sternotomy mediastinitis still devastating after the advent of negative-pressure wound therapy? Tex Heart Inst J 201 1;38:375-80.

51. Assmann A, Boeken $U$, Feindt $P$, Schurr $P$, Akhyari $P$, Lichtenberg $A$. Vacuum-assisted wound closure is superior to primary rewiring in patients with deep sternal wound infection. Thorac Cardiovasc Surg 2011;59:25-9.

52. Vos RJ, Yilmaz A, Sonker U, Kelder JC, Kloppenburg GT. Vacuumassisted closure of post-sternotomy mediastinitis as compared to open packing. Interact Cardiovasc Thorac Surg. 2012;14:17-21.

53. Deniz H, Gokaslan G, Arslanoglu Y, Ozcaliskan O, Guzel G, Yasim A Ustunsoy $\mathrm{H}$. Treatment outcomes of postoperative mediastinitis in cardiac surgery; negative pressure wound therapy versus conventional treatment. J Cardiothorac Surg 2012;7:67.

54. Fleck T, Fleck M. Negative pressure wound therapy for the treatment of sternal wound infections after cardiac surgery. Int Wound J 2014;11:240-5.

55. Risnes I, Abdelnoor M, Veel T, Svennevig JL, Lundblad R, Rynning SE. Mediastinitis after coronary artery bypass grafting: the effect of vacuum-assisted closure versus traditional closed drainage on survival and re-infection rate. Int Wound J 2014;11:177-82.

56. Steingrimsson S, Gottfredsson M, Gudmundsdottir I, Sjögren J, Gudbjartsson T. Negative-pressure wound therapy for deep sternal wound infections reduces the rate of surgical interventions for early re-infections. Interact Cardiovasc Thorac Surg 2012;15:406-10.

57. Raja SG, Berg GA. Should vacuum-assisted closure therapy be routinely used for management of deep sternal wound infection after cardiac surgery? Interact CardioVasc Thorac Surg 2007;6:523-7.

58. Schimmer C, Sommer SP, Bensch M, Elert O, Leyh R. Management of poststernotomy mediastinitis: experience and results of different therapy modalities. Thorac Cardiovasc Surg 2008;56:200-4.

59. Damiani G, Pinnarelli L, Sommella L, Tocco MP, Marvulli M, Magrini $P$, Ricciardi W. Vacuum-assisted closure therapy for patients with infected sternal wounds: a meta-analysis of current evidence. J Plast Reconstr Aesthet Surg 2011;64:1119-23.

60. Yu AW, Rippel RA, Smock E, Jarral OA. In patiens with post-sternotomy mediastinitisis vacuum-assistedclosure superior to conventional therapy? Interact Cardiovasc Thorac Surg 2013;17:861-5.

61. Falagas ME, Tansarli GS, Kapaskelis A, Vardakas KZ. Impact of vacuum-assisted closure (VAC) therapy on clinical outcomes of patients with sternal wound infections: a meta-analysis of non-randomized studies. PLoS One 2013;8:e64741.

62. Abu-Omar Y, Kocher GJ, Bosco P, Barbero C, Waller D, Gudbjartsson T, Sousa-Uva M, Licht PB, Dunning J, Schmid RA, Cardillo G. European Association for Cardio-Thoracic Surgery expert consensus statement on the prevention and management of mediastinitis. Eur J Cardiothorac Surg 2017;51:10-29.

63. Mokhtari A, Sjögren J, Nilsson J, Gustafsson R, Malmsjö M, Ingemansson $\mathrm{R}$. The cost of vacuum-assisted closure therapy in treatment of deep sternal wound infection. Scand Cardiovasc J 2008;42:85-9.

64. Tarzia V, Carrozzini M, Bortolussi G, Buratto E, Bejko J, Comisso M, Mescola V, Penzo V, Guarino M, De Franceschi M, Pagnin C, Castoro M, Guglielmi C, Testolin L, Bottio T, Gerosa G. Impact of vacuumassisted closure therapy on outcomes of sternal wound dehiscence. Interact Cardiovasc Thorac Surg 2014;19:70-5.

65. Gaudreau G, Costache V, Houde C, Cloutier D, Montalin L, Voisine $\mathrm{P}$, Baillot R. Recurrent sternal infection following treatment with negative pressure wound therapy and titanium transverse plate fixation.Eur J Cardiothorac Surg 2010;37:888-92.

66. Simek M, Molitor M, Kalab M, Tobbia P, Lonsky V. Current Challenges in the Treatment of Deep Sternal Wound Infection Following Cardiac
Surgery. In: Aronow WS, editor. Artery Bypass. Rijeka: Intech; 2013. p.493-539. ISBN 978-953-51-1025-5

67. Atkins BZ, Onaitis MW, Hutcheson KA, Kaye K, Petersen RP, Wolfe WG. Does method of sternal repair influence long-term outcome of postoperative mediastinitis? Am J Surg 2011;202:565-7.

68. Grapow M, Haug M, Tschung C, Winkler B, Banerjee P, Heinisch PP, Fassl J, Reuthebuch O, Eckstein F.Therapy options in deep sternal wound infection: Sternal plating versus muscle flap. PLoS One 2017;12:e0180024

69. Wang W, Wang S. Titanium plate fixation versus conventiona approach in the treatment of deep sternal wound infection. J Cardiothorac Surg 2016;11:46.

70. Robicsek F. Postoperative Sterno-mediastinitis. Am Surg 2000;66:184-92.

71. Santarpino G, Pollari F, Fischlein TJ. Sternal closure following negative pressure wound therapy: a safe approach with a new titanium device. Int J Artif Organs 2014;37:264-9.

72. Piotrowski JA, Fischer M, Klaes W, Splittgerber F. Autologous bone transplant after sternal resection. J Cardiovasc Surg (Torino) 1996;37:179-81.

73. Nahabedian MY, Riley LH, Greene PS, Yang SC, Vander CA, Greene PS. Sternal stabilization using allograft fibula following cardiac transplantation. Plastic Reconstr Surg 2001;108:1284-8.

74. Marulli G, Hamad AM, Cogliati E, Breda C, Zuin A, Rea F. Allograft sternochondral replacement after resection of large sternal chondrosarcoma.J Thorac Cardiovasc Surg 2010;139:e69-70.

75. Dell'Amore A, Dolci G, Cassanelli N, Bini A, Stella F. A massive poststernotomy sternal defect treated by allograft sternal transplantation. J Card Surg 2012;27:557-9.

76. Kalab M, Molitor M, Kubesova B, Lonsky V. Use of allogenous bone graft and osteosynthetic stabilization in treatment of massive poststernotomy defects. Eur J Cardiothorac Surg 2012;41:e182-4.

77. Kalab M, Karkoska J, Kaminek M, Santavý P. Transplantation of allogeneic bone graft in the therapy of massive post-sternotomy defects - 6 years of experience with the method. Rozhl Chir 2016;95:399-406.

78. European Association of Tissue Banks. General Standards for Tissue Banking. ÖBIG-Transplant, Vienna, 1995.

79. Krüger M, Zinne N, Zhang R. Multidirectional thoracic wall stabilization: a new device on the scene. Ann Thorac Surg 2013;96:1846-9.

80. Ceresa F, Casablanca G, Patanè F. Complicated sternal dehiscence treated with the strasbourg thoracic osteosyntheses system (STRATOS) and the transposition of greater omentum: a case report. J Cardiothorac Surg 2010;5:53.

81. Khoynezhad A, Abbas G, Palazzo RS, Graver LM. Spontaneous right ventricular disruption following treatment of sternal infection J Card Surg 2004;19:74-8.

82. Sue G, Price G, Stahl R, Teng E, Narayan D. Major Bleeding in Patients with Mediastinitis: A Heartbreaking Series. Thorac Cardiovasc Surg 2015;63:73-6.

83. Niclauss L, Delay D, Stumpe F. Right ventricular rupture due to recurrent mediastinal infection with a closed chest. Interact Cardiovasc Thorac Surg 2010;10:470-2.

84. van Wingerden JJ, Segers P, Jekel L. Major bleeding during negative pressure wound/V.A.C. ${ }^{\circledR}$--therapy for postsurgical deep sternal wound infection--a critical appraisal. Heart Surg Forum 2012;15:E257-61.

85. Petzina R, Malmsjö M, Stamm C, Hetzer R. Major complications during negative pressure wound therapy in poststernotomy mediastinitis after cardiac surgery. J Thorac Cardiovasc Surg 2010;140:1133-6.

86. Sjögren J, Gustafsson R, Nilsson J, Lindstedt S, Nozohoor S Ingemansson R. Negative-pressure wound therapy following cardiac surgery: bleeding complications and 30-day mortality in 176 patients with deep sternal wound infection. Interact Cardiovasc Thorac Surg 2011;12:117-20.

87. Ingemansson R, Malmsjö M, Lindstedt S. The HeartShield device reduces the risk for right ventricular damage in patients with deep sternal wound infection. Innovations (Phila) 2014;9:137-41.

88. Ingemansson $\mathrm{R}$, Malmsjö $M$, Lindstedt $S$. The duration of negative pressure wound therapy can be reduced using the HeartShield device in patients with deep sternal wound infection. Eplasty 2014;14:e16.

89. Lindstedt S, Malmsjö M, Ingemansson R. C-reactive protein and leucocyte counts drop faster using the HeartShield ${ }^{\circledR}$ device in patients with DSWI. Int Wound J 2015;12:189-94. 
90. Steingrímsson S, Gustafsson R, Gudbjartsson T, Mokhtari A Ingemansson R, Sjögren J. Sternocutaneous fistulas after cardiac surgery: incidence and late outcome during a ten-year follow-up. Ann Thorac Surg 2009;88:1910-14
91. Bapat V, El-Muttardi N, Young C, Venn G, Roxburgh J. Experience with Vacuum-assisted closure of sternal wound infections following cardiac surgery and evaluation of chronic complications associated with its use. J Card Surg 2008;23:227-33. 